\title{
MASSA DE FORRAGEM E CARACTERÍSTICAS ESTRUTURAIS E BROMATOLÓGICAS DE CULTIVARES DE Brachiaria E Panicum
}

\section{DRY MATTER PRODUCTION AND STRUCTURAL AND BROMATOLOGICAL CHARACTERISTICS OF Brachiaria AND Panicum CULTIVARS}

\author{
Janaina de Lima Silva ${ }^{1 *}$ \\ Karina Guimarães Ribeiro ${ }^{2}$ \\ Bruna Nogueira Herculano ${ }^{3}$ \\ Odilon Gomes Pereira ${ }^{2}$ \\ Rosana Cristina Pereira ${ }^{4}$ \\ Luciana Felizardo Pereira Soares ${ }^{1}$ \\ ${ }^{1}$ Universidade Federal Rural de Pernambuco, Recife, PE, Brasil. \\ ¿Universidade Federal de Viçosa, Viçosa, MG, Brasil. \\ ${ }^{3}$ Universidade Federal dos Vales de Jequitinhonha e Mucuri, Diamantina, MG, Brasil. \\ ${ }^{4}$ Instituto Federal Fluminense, Bom Jesus do Itabapoana, RJ, Brasil \\ *Autora para correspondência - silva_janainalima@yahoo.com.br
}

\section{Resumo}

Objetivou-se avaliar as características estruturais, a produção de massa seca e a composição bromatológica de cultivares de Brachiaria e Panicum. O estudo foi conduzido em casa-de-vegetação, em delineamento em blocos casualizados, com cinco tratamentos, sendo três cultivares de Brachiaria (B. decumbens cv. Basilisk, B. brizantha cv. Marandu e cv. Xaraés) e dois cultivares de Panicum (P. maximum cv. Mombaça e cv. Tanzânia), com quatro repetições. De modo geral, maior número de folhas, comprimento laminar e perfilhos foram verificados nas cultivares Mombaça, Tanzânia e Basilisk. As cultivares Tanzânia e Mombaça se destacaram na produção de massa seca, em relação a cv. Marandu, com as outras cultivares com posição intermediária, enquanto a cultivar Xaraés apresentou a maior relação lâmina/colmo. Não houve diferenças nos teores de proteína bruta entre as cultivares, enquanto os teores de fibra em detergente neutro e fibra em detergente ácido foram inferiores para Marandu e Xaraés. Com base nos resultados, todas as cultivares poderiam ser recomendadas, atendendo-se às suas diferentes exigências nutricionais,

Palavras-chave: comprimento de folhas; fibra em detergente neutro; número de folhas; perfilhos; proteína bruta.

\begin{abstract}
The aim of this study was to evaluate the dry matter production and the structural and bromatological characteristics of Brachiaria and Panicum cultivars. The study was conducted in a greenhouse in a randomized complete block design with five treatments, three cultivars of Brachiaria (B. decumbens cv. Basilisk, B. brizantha cv. Marandu and cv. Xaraes) and two cultivars of Panicum (P. maximum cv. Mombaça and cv. Tanzania), with four replications. Higher number of leaves, greater laminar length and tillers were observed in Mombaça, Tanzania, and Basilisk cultivars. Tanzania and Mombaça cultivars showed higher production of dry mass in relation to Marandu, and Xaraes cultivar showed higher leaf/stem ratio. There was no difference in crude protein content among cultivars, while neutral detergent fiber and acid detergent fiber content was lower for Marandu and Xaraes. We recommend all the cultivars considering their different nutritional requirements.
\end{abstract}

Keywords: crude protein; laminar length; neutral detergent fiber; number of leaves; tillers. 
Enviado em: 21 novembro 2014

Aceito em: 25 abril de 2016

\section{Introdução}

O gênero Brachiaria caracteriza-se pela alta produção de matéria seca, facilidade de estabelecimento, adequado valor nutritivo e crescimento inclusive no período $\operatorname{seco}^{(1)}$. As gramíneas do gênero Panicum, assim como as braquiárias, estão entre as forrageiras mais utilizadas em sistema de produção animal no Brasil, devido à elevada produtividade e bom valor nutritivo ${ }^{(2)}$.

A escolha incorreta da espécie ou cultivar forrageira pode promover desequilíbrio do bioma e, ao longo do tempo, baixos índices de produtividade e de qualidade ${ }^{(3)}$. Assim, é importante estudar as características estruturais do dossel forrageiro (tamanho de folhas, número de folhas por perfilhos e densidade de perfilhos) que determinam a produtividade da gramínea $^{(4)}$ e a relação folha/colmo ${ }^{(5)}$, por estarem associadas à facilidade com que os animais colhem a forragem preferida (folhas), o que se correlacionada com o valor nutritivo ${ }^{(6)}$.

A avaliação da composição bromatológica, além das características estruturais, permite estimar o valor nutritivo. A fração fibrosa e a proteica são comumente afetadas pela espécie ou cultivar, fertilidade do solo e idade da planta ${ }^{(7)}$.

Em razão da relevância dos gêneros Brachiaria e Panicum entre as forrageiras cultivadas no Brasil, é oportuno compará-las numa mesma condição, para o melhor entendimento das respostas ao manejo. Assim, objetivou-se avaliar a produção de massa seca, as características estruturais e a composição bromatológica das espécies Brachiaria decumbens cv. Basilisk, Brachiaria brizantha cvs. Marandu e Xaraés e Panicum maximum cvs. Mombaça e Tanzânia.

\section{Material e Métodos}

O estudo foi conduzido em casa-de-vegetação, situada no Setor de Forragicultura do Departamento de Zootecnia, na Universidade Federal dos Vales do Jequitinhonha e Mucuri/UFVJM, Campus JK, Diamantina, Minas Gerais. O Campus JK localiza-se a aproximadamente $1400 \mathrm{~m}$ de altitude, $18^{\circ}$ 9' S de latitude e $43^{\circ} 21^{\prime}$ WGR. O tipo climático é Cwb (temperado quente com inverno seco), segundo classificação de Köppen. Durante o estudo, as temperaturas médias máximas e mínimas observadas na casa-de-vegetação foram de 32,5 e $15,8^{\circ} \mathrm{C}$, respectivamente.

Utilizou-se solo Neossolo Quartzarênico Órtico típico, predominante na região, coletado no Setor de Forragicultura na camada de 0 a $20 \mathrm{~cm}$, o qual foi seco, peneirado em malha de 4,0 $\mathrm{mm}$ e amostrado para análise química. As características do solo utilizado foram: $\mathrm{pH}\left(\mathrm{H}_{2} \mathrm{O}\right)=5,8 ; \mathrm{P}, \mathrm{K}, \mathrm{Ca}, \mathrm{Mg}, \mathrm{Al}$, $\mathrm{H}+\mathrm{Al}$, soma de bases, CTC efetiva e CTC a pH 7,0, respectivamente, 0,$9 ; 14 ; 0,9 ; 0,4 ; 0,2 ; 2,4$; 1,$3 ; 1,5$ e $3,7 \mathrm{cmol}_{\mathrm{c}} \cdot \mathrm{dm}^{-3}$; saturação de alumínio e saturação de bases, respectivamente, 13 e $36 \%$; e matéria orgânica 0,8 dag. $\mathrm{kg}^{-1}$.

O delineamento experimental utilizado foi em blocos casualizados, com cinco tratamentos (forrageiras) e quatro repetições. Foram estudados três cultivares de Brachiaria (B. decumbens cv. Basilisk, $B$. brizantha cvs. Marandu e Xaraés) e dois cultivares de Panicum (P. maximum cvs. Mombaça e Tanzânia), totalizando 20 unidades experimentais.

A semeadura das forrageiras foi realizada diretamente nos vasos, com capacidade para $5,0 \mathrm{dm}^{3} \mathrm{de}$ solo, utilizando-se 15 sementes de cultivares de Brachiaria e 25 sementes de cultivares de Panicum, por vaso. Cada vaso foi previamente incubado com dose equivalente a $300 \mathrm{mg} / \mathrm{dm}^{3}$ de $\mathrm{P}_{2} \mathrm{O}_{5}$ e irrigado diariamente.

Aos 21 dias após a semeadura, realizou-se um desbaste, deixando-se oito plantas por vaso e 
aplicando-se, em seguida, $50 \mathrm{mg} / \mathrm{dm}^{3}$ de $\mathrm{N}$ e $50 \mathrm{mg} / \mathrm{dm}^{3}$ de $\mathrm{K}_{2} \mathrm{O}$. Após 33 dias realizou-se o segundo desbaste, deixando-se cinco plantas por vaso, das quais três foram identificadas com linhas coloridas para as avaliações estruturais. Em seguida, realizou-se o corte de uniformização a $5 \mathrm{~cm}$ do nível do solo e aplicaram-se doses de $100 \mathrm{mg} / \mathrm{dm}^{3}$ de $\mathrm{N}$ e $100 \mathrm{mg} / \mathrm{dm}^{3}$ de $\mathrm{K}_{2} \mathrm{O}$, utilizando-se como fontes o sulfato de amônio e o cloreto de potássio, respectivamente.

O acompanhamento das plantas foi realizado semanalmente e, aos 41 dias de rebrotação, foram avaliadas as características estruturais nas plantas identificadas. Para as avaliações de produção de massa seca e da composição bromatológica, colheram-se todas as plantas de cada vaso, ao nível do solo. As características avaliadas por planta foram: 1) número total de folhas: somatório de folhas emergentes, completamente expandidas, senescentes e mortas; 2) número de folhas completamente expandidas: somatório das folhas que apresentaram a lígula exposta; 3) número total de folhas senescentes: somatório de folhas senescentes e mortas; 5) número de folhas vivas: diferença entre número total de folhas e número total de folhas senescentes; 6) número de perfilhos por perfilho principal: somatório do número de perfilhos; 7) comprimento laminar acumulado $(\mathrm{cm})$ : somatório dos comprimentos do ápice foliar até a lígula; 8) produção de massa seca (g por vaso): massa da parte aérea das plantas de cada vaso; 9) relação lâmina/colmo: razão de massa seca de lâminas e massa seca de colmos; 10 ) absorção de nitrogênio (g de N por vaso): teor de $\mathrm{N}(\% \mathrm{MS})$ x produção de massa seca por vaso (g); e 11) vigor de rebrotação (g de MS por vaso): produção da rebrotação obtida em corte efetuado aos 21 dias após a colheita das plantas.

Para determinação da amostra seca ao ar, as amostras de lâminas e de colmos + bainhas foram présecas em estufa com ventilação forçada de ar a $55^{\circ} \mathrm{C}$, por 72 horas. Em seguida, as amostras foram pesadas separadamente e moídas juntas (lâminas + colmos + bainhas), por unidade experimental, em moinho tipo "Willey", sendo armazenadas em recipientes fechados para posteriores análises laboratoriais.

Os teores de matéria seca (MS), proteína bruta (PB), fibra em detergente neutro (FDN) e fibra em detergente ácido (FDA) foram determinados segundo metodologia descrita por Detmann et al. ${ }^{(8)}$. A produção de massa natural por vaso foi corrigida para produção de massa seca por vaso.

Os dados foram submetidos à análise de variância e ao teste de Tukey, ao nível de $5 \%$ de probabilidade, utilizando-se o Sistema de Análises Estatísticas - SAEG ${ }^{(9)}$.

\section{Resultados e Discussão}

Diversos fatores influenciam a disponibilidade de lâmina foliar para o animal, como luz, temperatura, água e quantidade de nutrientes, devido aos efeitos sobre o processo de fotossíntese e a dinâmica de crescimento e desenvolvimento de perfilhos, sendo desejável maior proporção de lâminas foliares em uma espécie forrageira. Sendo assim, o manejo do pastejo com base nas características estruturais do dossel é importante para que a maior parte da forragem consumida pelo animal seja composta por lâminas foliares, uma vez que apresentam melhor valor nutritivo que os colmos ${ }^{(10)}$.

As cultivares Basilisk, Mombaça e Tanzânia apresentaram média de 35 folhas por planta, demonstrando a maior capacidade de produção de folhas que as cultivares Marandu e Xaraés (Tabela 1).

A comparação das forrageiras em relação ao número de folhas completamente expandidas (FCE) reforçou o maior valor para a cultivar Basilisk $(28,91)$ em relação à cultivar Marandu, porém, sem diferir das cultivares Xaraés, Mombaça e Tanzânia, que apresentaram valores semelhantes e intermediários entre as outras duas cultivares (Tabela 1).

Os números de folhas vivas por planta, de 35,65; 32,24 e 26,48, mantiveram-se superiores para Basilisk, Mombaça e Tanzânia, respectivamente, em relação as cultivares Marandu e Xaraés (Tabela 1). Não foram observadas diferenças entre as cultivares quanto ao número de folhas senescentes e mortas, avaliado por planta, verificando-se valor médio de 3,73. 
Tabela 1. Características estruturais de cultivares do gênero Brachiaria e Panicum

\begin{tabular}{lcccccc}
\hline Variável & Basilisk & Marandu & Xaraés & Mombaça & Tanzânia & CV(\%) \\
\cline { 2 - 6 } Total de folhas $\left(\mathrm{n}^{\circ}\right)$ & $40,40 \mathrm{a}$ & $15,60 \mathrm{~b}$ & $13,32 \mathrm{~b}$ & $35,07 \mathrm{a}$ & $29,40 \mathrm{a}$ & 19,69 \\
Folhas completamente expandidas $\left(\mathrm{n}^{\circ}\right)$ & $28,91 \mathrm{a}$ & $9,66 \mathrm{~b}$ & $13,66 \mathrm{ab}$ & $16,75 \mathrm{ab}$ & $12,75 \mathrm{ab}$ & 49,77 \\
Folhas vivas $\left(\mathrm{n}^{\circ}\right)$ & $35,65 \mathrm{a}$ & $10,52 \mathrm{~b}$ & $10,24 \mathrm{~b}$ & $32,24 \mathrm{a}$ & $26,48 \mathrm{a}$ & 21,62 \\
Folhas senescentes e mortas $\left(\mathrm{n}^{\circ}\right)$ & $4,75 \mathrm{a}$ & $5,08 \mathrm{a}$ & $3,08 \mathrm{a}$ & $2,83 \mathrm{a}$ & $2,92 \mathrm{a}$ & 28,18 \\
Comprimento laminar acumulado $(\mathrm{cm})$ & $259,44 \mathrm{a}$ & $72,12 \mathrm{c}$ & $76,68 \mathrm{bc}$ & $288,26 \mathrm{a}$ & $221,65 \mathrm{ab}$ & 35,36 \\
Perfilhos $\left(\mathrm{n}^{\circ}\right)$ & $10,16 \mathrm{a}$ & $4,58 \mathrm{~b}$ & $3,91 \mathrm{~b}$ & $9,33 \mathrm{a}$ & $6,16 \mathrm{ab}$ & 30,25 \\
\cline { 2 - 6 } & \multicolumn{6}{c}{ Avaliação por perfilho } \\
\cline { 2 - 6 } Total de folhas $\left(\mathrm{n}^{\circ}\right)$ & $4,01 \mathrm{ab}$ & $3,28 \mathrm{~b}$ & $3,35 \mathrm{~b}$ & $4,41 \mathrm{a}$ & $4,80 \mathrm{a}$ & 11,67 \\
Folhas completamente expandidas $\left(\mathrm{n}^{\circ}\right)$ & $2,84 \mathrm{a}$ & $2,20 \mathrm{ab}$ & $1,71 \mathrm{~b}$ & $2,00 \mathrm{~b}$ & $1,95 \mathrm{~b}$ & 15,53 \\
Folhas vivas $\left(\mathrm{n}^{\circ}\right)$ & $3,49 \mathrm{ab}$ & $1,73 \mathrm{c}$ & $2,26 \mathrm{bc}$ & $3,91 \mathrm{a}$ & $4,10 \mathrm{a}$ & 22,77 \\
Folhas senescentes e mortas $\left(\mathrm{n}^{\circ}\right)$ & $0,52 \mathrm{~b}$ & $1,55 \mathrm{a}$ & $1,09 \mathrm{ab}$ & $0,50 \mathrm{~b}$ & $0,69 \mathrm{ab}$ & 50,66 \\
Comprimento laminar acumulado $(\mathrm{cm})$ & $24,73 \mathrm{ab}$ & $13,68 \mathrm{~b}$ & $16,98 \mathrm{~b}$ & $34,48 \mathrm{a}$ & $33,84 \mathrm{a}$ & 23,47 \\
\hline
\end{tabular}

Médias seguidas de mesma letra nas linhas não diferem pelo teste de Tukey $(\mathrm{p}<0,05)$.

As cultivares Basilisk e Mombaça apresentaram superioridade quanto ao comprimento laminar acumulado (259,44 e 288,26 cm), porém, sem diferir da cultivar Tanzânia, que, por sua vez, não diferiu das cultivares Marandu e Xaraés.

A produção de perfilhos e a duração do perfilhamento variam entre espécies e cultivares, podendo ser influenciadas por fatores nutricionais, ambientais e de manejo. As cultivares Basilisk e Mombaça apresentaram maior número de perfilhos por planta (10,16 e 9,33, respectivamente), sem diferir, contudo, da cultivar Tanzânia (Tabela 1), que não diferiu das cultivares Marandu e Xaraés, dado que demonstra a alta capacidade de perfilhamento da cultivar Basilisk. A produção de novos perfilhos, de acordo com Garcez Neto et al. ${ }^{(11)}$, é um processo contínuo que pode ser acelerado pela desfolhação da planta e consequente melhoria do ambiente luminoso na base do dossel. A manutenção da população de perfilhos ocorre por uma contínua reposição dos perfilhos mortos pelos vivos, sendo esse comportamento essencial para a perenidade das gramíneas.

Em relação à avaliação por perfilho, o número total de folhas (NTF) e o número de folhas vivas foram semelhantes e superiores nas cultivares Mombaça e Tanzânia, sem diferir da cultivar Basilisk (Tabela 1). Contudo, a cultivar Basilisk apresentou o maior número de folhas completamente expandidas (NFE) por perfilho, não diferindo da Marandu (Tabela 1).

As cultivares Basilisk e Mombaça apresentaram menores números de folhas mortas (NFM) por perfilho do que a cv. Marandu, que, por sua vez, não diferiu das cultivares Xaraés e Tanzânia (Tabela 1). Cano et al. ${ }^{(12)}$ verificaram que quanto maior a massa de forragem verde maior o IAF, o que esteve associado às maiores perdas por senescência, como consequência da baixa utilização da forragem produzida.

Os comprimentos laminares acumulados por perfilho para as cultivares Tanzânia e Mombaça, foram superiores às cultivares de Marandu e Xaraés, enquanto a cv. Basilisk apresentou média intermediária (Tabela 1). Segundo Gomide \& Gomide ${ }^{(13)}$, o comprimento laminar é maior em folhas com inserção intermediária no perfilho, provavelmente em função do comprimento do pseudocolmo. Dessa forma, o maior comprimento laminar final em plantas mais altas, como as cultivares de Panicum maximum, pode ser explicado pelo maior tamanho dos perfilhos. Segundo Skinner \& Nelson ${ }^{(14)}$, em perfilhos maiores, a maior distância percorrida pela folha, desde o ponto de conexão com o meristema até a extremidade do pseudocolmo, resulta no seu maior comprimento. $\mathrm{O}$ alongamento do pseudocolmo nos pastos de capim-marandu com maior altura, segundo Calvano et al. ${ }^{(15)}$, pode ser resultado da elevada competição por luz entre os perfilhos nesse local. 
As cultivares Mombaça (27,11 g por vaso) e Tanzânia (27,92 g por vaso) apresentaram maior produção total de massa seca do que a Marandu (17,75 g por vaso), enquanto Basilisk (21,49 g por vaso) e Xaraés $(24,04$ g por vaso) apresentaram resultados intermediários (Tabela 2). A produção de massa seca de lâminas nas cultivares Xaraés e Tanzânia foi maior do que para a cv. Basilisk; entretanto, não diferiu das cultivares Mombaça e Marandu, verificando-se menor produção média de colmos para Marandu e Xaraés.

Tabela 2. Características produtivas, teor e absorção de nitrogênio de cultivares do gênero Brachiaria e Panicum

\begin{tabular}{lcccccc}
\hline Variável & Basilisk & Marandu & Xaraés & Mombaça & Tanzânia & CV (\%) \\
\hline $\begin{array}{l}\text { Produção de MS (g por vaso) } \\
\text { Produção de MS de lâminas (g }\end{array}$ & $21,49 \mathrm{ab}$ & $17,75 \mathrm{~b}$ & $24,04 \mathrm{ab}$ & $27,11 \mathrm{a}$ & $27,92 \mathrm{a}$ & 16,72 \\
por vaso) & $10,97 \mathrm{~b}$ & $12,16 \mathrm{ab}$ & $17,08 \mathrm{a}$ & $16,18 \mathrm{ab}$ & $17,49 \mathrm{a}$ & 17,62 \\
$\begin{array}{l}\text { Produção de MS de colmos (g } \\
\text { por vaso) }\end{array}$ & $10,52 \mathrm{a}$ & $5,59 \mathrm{~b}$ & $6,97 \mathrm{~b}$ & $10,93 \mathrm{a}$ & $10,43 \mathrm{a}$ & 16,22 \\
Relação lâmina/colmo & $1,05 \mathrm{~d}$ & $2,20 \mathrm{~b}$ & $2,45 \mathrm{a}$ & $1,47 \mathrm{c}$ & $1,67 \mathrm{c}$ & 6,03 \\
Teor de nitrogênio (\%) & 1,53 & 1,49 & 1,50 & 1,37 & 1,37 & 9,09 \\
Absorção de N (g por vaso) & $0,33 \mathrm{ab}$ & $0,26 \mathrm{~b}$ & $0,36 \mathrm{ab}$ & $0,37 \mathrm{ab}$ & $0,38 \mathrm{a}$ & 15,16 \\
\hline
\end{tabular}

Médias seguidas de mesma letra nas linhas não diferem pelo teste de Tukey $(\mathrm{p}<0,05)$

De acordo com Euclides et al. ${ }^{(16)}$, o comportamento ingestivo e o desempenho animal são afetados principalmente pelas características estruturais do dossel forrageiro, em particular a proporção de folhas, por estar correlacionada ao valor nutritivo da forragem produzida. Assim, as cultivares Xaraés, Mombaça e Tanzânia apresentaram tanto mais elevada produção de massa seca quanto mais alta contribuição em lâminas, fornecendo um material mais digestível.

Melhor relação lâmina/colmo foi obtida para a cv. Xaraés $(2,45)$ em relação às demais cultivares, 0 que representa $71 \%$ de folhas na massa de forragem (Tabela 2). Esse resultado é importante, já que o acúmulo de lâmina foliar verde pode favorecer o desempenho animal ${ }^{(17)}$.

$\mathrm{O}$ teor de nitrogênio $(\mathrm{N})$ não diferiu entre as cultivares estudadas, com valor médio observado de 1,45\% (Tabela 2). Verificou-se mais alta absorção de nitrogênio para a cv. Tanzânia em relação a cv. Marandu, enquanto as outras cultivares apresentaram resultados intermediários. Este parâmetro foi mais influenciado pela produção de massa seca das diferentes espécies e cultivares, pois os teores de nitrogênio não diferiram entre elas.

A análise da composição bromatológica dos gêneros Brachiaria e Panicum indicou diferenças entre as cultivares, com maior teor de matéria seca (MS) para a cultivar Xaraés e o mais baixo teor para a cv. Basilisk (Tabela 3). No entanto, não houve efeito para os teores de proteína bruta (PB), com valores médios de 9,07\%, o qual foi considerado satisfatório para as condições de clima tropical, haja vista que teores mínimos de $7,0 \%$ são exigidos para o adequado funcionamento do rúmen.

Os mais baixos teores de fibra em detergente neutro (FDN) e fibra em detergente ácido (FDA) foram obtidos para as cultivares de $B$. brizantha (Tabela 3 ), resultados que estiveram relacionados à menor produção de colmos (Tabela 2); entretanto, as outras cultivares apresentaram teores de FDN dentro da faixa normalmente obtida para forrageiras de clima tropical. Os teores de FDA obtidos para essas cultivares apresentaram resultados semelhantes.

Na rebrotação aos 21 dias, mais altos teores de MS foram observados para Basilisk, que não diferiu das cultivares Xaraés e Mombaça (Tabela 3). Já a produção de massa seca não diferiu entre as cultivares estudadas, com valor médio de 3,73 g por vaso (Tabela 3). 
Tabela 3. Composição bromatológica e vigor de rebrotação de cultivares do gênero Brachiaria e Panicum

\begin{tabular}{lcccccc}
\hline Variável & Basilisk & Marandu & Xaraés & Mombaça & Tanzânia & CV \\
\hline Matéria seca (\%) & $14,00 \mathrm{c}$ & $18,05 \mathrm{~b}$ & $20,20 \mathrm{a}$ & $18,17 \mathrm{ab}$ & $18,99 \mathrm{ab}$ & 5,22 \\
Proteína bruta (\%MS) & 9,56 & 9,31 & 9,35 & 8,56 & 8,60 & 9,09 \\
Fibra em detergente neutro (\%MS) & $62,65 \mathrm{a}$ & $56,33 \mathrm{~b}$ & $58,21 \mathrm{~b}$ & $64,58 \mathrm{a}$ & $65,29 \mathrm{a}$ & 2,40 \\
Fibra em detergente ácido (\%MS) & $27,46 \mathrm{a}$ & $24,05 \mathrm{~b}$ & $24,80 \mathrm{~b}$ & $28,51 \mathrm{a}$ & $28,70 \mathrm{a}$ & 2,08 \\
\cline { 2 - 6 } & \multicolumn{5}{c}{ Rebrotação (21 dias após a colheita) } \\
\cline { 2 - 6 } Matéria seca (\%) & $21,51 \mathrm{a}$ & $19,47 \mathrm{bc}$ & $21,33 \mathrm{ab}$ & $20,64 \mathrm{abc}$ & $19,20 \mathrm{c}$ & 4,33 \\
Produção de massa seca (g por vaso) & 3,52 & 3,35 & 4,66 & 3,22 & 3,89 & 29,14 \\
\hline
\end{tabular}

Médias seguidas de mesma letra nas linhas não diferem pelo teste de Tukey $(\mathrm{p}<0,05)$

\section{Conclusões}

Com base nos resultados obtidos, todas as cultivares poderiam ser recomendadas atendendo-se às suas diferentes exigências nutricionais.

\section{Referências}

1. Costa KA de P, Rosa B, Oliveira IP de, Custódio DP, Silva DC. Efeito da estacionalidade na produção de matéria seca e composição bromatológica da Brachiaria brizantha cv. Marandu [Effect of seasonal climate condition on the dry matter production and bromatological composition of Brachiaria brizantha cv. Marandu]. Ciência Animal Brasileira [Internet]. 2005; 6(3):187-193. Available from: http://www.revistas.ufg.br/index.php/ vet/article/view/365/340. Portuguese.

2. Gomes RA, Lempp B, Jank L, Carpejani GC, Morais MG. Características anatômicas e morfofisiológicas de lâminas foliares de genótipos de Panicum maximum [Anatomical and morphophysiological leaf blade traits of Panicum maximum genotypes]. Pesquisa Agropecuária Brasileira [Internet]. 2011; 46(2):205-211. Available from: http://www.scielo.br/pdf/pab/v46n2/v46n02a13.pdf. Portuguese.

3. Bauer MO, Pacheco LPA, Chichorro JF, Vasconcelos LV, Pereira DFC. Produção e características estruturais de cinco forrageiras do gênero Brachiaria sob intensidades de cortes intermitentes [Herbage yield and structural characteristics of five Brachiaria genus forages under intermittently defoliation sward]. Ciência Animal Brasileira [Internet]. 2011; 12(1):17-25. Available from: DOI: 10.5216/cab.v12i1.4817. Portuguese.

4. Alves JS, Pires AJV, Matsumoto SN, Figueiredo MP, Ribeiro GS. Características morfológicas e estruturais da Brachiaria decumbens Stapf. submetida a diferentes doses de nitrogênio e volumes de água [Morphological and structural characteristics of Brachiaria decumbens Stapf. submitted to different nitrogen doses and water volumes]. Acta Veterinaria Brasilica [Internet]. 2008; 2(1):1-10. Available from: http://periodicos.ufersa.edu.br/ revistas/index.php/acta/article/view/599/296. Portuguese.

5. Gontijo Neto, M.M.; Euclides, V.P.B.; Nascimento Júnior, D.; Miranda, L.F.; Fonseca, D.M.; Oliveira, M.P. Consumo e tempo diário de pastejo por novilhos Nelore em pastagem de capim Tanzânia sob diferentes ofertas de forragem [Effects of herbage allowance on the intake and grazing time of Nellore steers grazing tanzâniagrass pasture]. Revista Brasileira de Zootecnia [Internet]. 2006; 35:60-66. Available from: http://dx.doi.org/10.1590/ S1516-35982006000100007. Portuguese.

6. Castagnara DD, Mesquita EE, Neres MA, Oliveira PSR, Deminicis BB, Bamberg R. Valor nutricional e características estruturais de gramíneas tropicais sob adubação nitrogenada [Nutritional value and structural characteristics of tropical grasses under nitrogen fertilization]. Archivos de Zootecnia [Internet]. 2011; 60 (232):931-941. Available from: http://www.uco.es/organiza/servicios/publica/az/php/img/ web/18_19_12_10ComposicaoCastagnara.pdf. Portuguese. 
7. Van Soest PJ, Robertson JB, Lewis BA. Methods for dietary fiber, neutral detergent fiber, and nonstarch polysacharides in relation to animal nutrition. Journal of Dairy Science. 1991; 74:3583-3597.

8. Detmann E, Souza MA de, Valadares Filho SC, Queiroz AC de, Berchielli TT, Saliba EOS, Cabral LS, Pina DS, Ladeira MM, Azevedo JAG. Métodos para Análise de Alimentos. Instituto Nacional de Ciência e Tecnologia de Ciência Animal. (Suprema, Visconde do Rio Branco). 2012.

9. Universidade Federal de Viçosa - UFV. Sistema de análises estatísticas e genéticas - SAEG. Versão 8.0. Viçosa, MG; 2007. 142p. Portuguese.

10. Trindade JK, Silva SC, Souza Júnior SJ, Giacomini AA, Zeferino CV, Guarda VDA, Carvalho PCF. Composição morfológica da forragem de capim-marandu consumida por bovinos de corte em pastejo rotativo. [Morphological composition of marandu palisadegrass herbage consume by beef cattle subjected to rotational grazing]. Pesquisa Agropecuária Brasileira [Internet]. 2007; 42(6):883-890. Available from: http://www.scielo. br/pdf/pab/v42n6/v42n6a16.pdf. Portuguese.

11. Garcez Neto AF, Nascimento Junior D, Regazzi AJ, Fonseca DM, Mosquim PR, Gobbi KF. Respostas morfogênicas e estruturais de Panicum maximum cv. Mombaça sob diferentes níveis de adubação nitrogenada e alturas de corte [Morphogenetic and structural responses of Panicum maximum cv. Mombaça on different levels of nitrogen fertilization and cutting regimes]. Revista Brasileira de Zootecnia [Internet]. 2002; 31(5):1890-1900. Available from: http://www.scielo.br/pdf/rbz/v31n5/a04v31n5.pdf. Portuguese.

12. Cano CCP, Cecato U, Canto MW, Rodrigues AB, Jobim CC, Rodrigues AM, Galbeiro S, Nascimento WG. Pastejo de forragem do capim-tanzânia (Panicum maximum Jacq. cv. Tanzânia-1) pastejado em diferentes alturas [Forage production of tanzaniagrass (Panicum maximum Jacq. cv. Tanzânia-1) grazed at different Heights]. Revista Brasileira de Zootecnia [Internet]. 2004; 33(6):1949-1958. Available from: http://www.scielo.br/pdf/rbz/ v33n6s2/23298.pdf. Portuguese.

13. Gomide JA, Gomide CAM. Morfogênese de cultivares de Panicum maximum Jacq [Morphogenesis of Panicum maximum Jacq. Cultivars]. Revista Brasileira de Zootecnia [Internet]. 2000; 29(2):341-348. Available from: http://dx.doi.org/10.1590/S1516-35982000000200004. Portuguese.

14. Skinner RH, Nelson CJ. Elongation of the grass leaf and its relationship phillochron. Crop Science. 1995; 35(1):4-10.

15. Calvano MPCA, Euclides VPB, Montagner DB, Lempp B, Difante GS, Flores RS, Galbeiro S. Tillering and forage accumulation in Marandu grass under different grazing intensities. Revista Ceres [Internet]. 2011; 58(6):781-789. Available from: http://www.scielo.br/pdf/rceres/v58n6/15.pdf . Portuguese.

16. Euclides VPB, Valle CB, Silva JM da, Vieira A. Avaliação de forrageiras tropicais manejadas para produção de feno em pé [Evaluation of tropical forages managed for stockpiling purposes]. Pesquisa Agropecuária Brasileira [Internet]. 1990; 25:393-407. Available from: http://seer.sct.embrapa.br/index.php/pab/article/view/13422/7556. Portuguese.

17. Cabral WB, Souza AL, Alexandrino E, Toral FLB, Santos JN, Carvalho MVP. Características estruturais e agronômicas da Brachiaria brizantha cv. Xaraés submetida a doses de nitrogênio [Structural characteristics and agronomic traits of Brachiaria brizantha cv. Xaraés subjected to nitrogen levels]. Revista Brasileira de Zootecnia [Internet]. 2012; 41(4):846-855. Available from: http://www.scielo.br/pdf/rbz/v41n4/04.pdf. Portuguese. 